\title{
Entre historietas y libros
}

doi: http://dx.doi.org/10.32870/espiral.v23i65.4462.g4204

Agustín Vaca*

Hasta mediados del siglo Xx no existía mayor dificultad para entender a qué se hacía referencia cuando se hablaba de literatura, así nomás, sin apellido. Se hablaba de los grandes logros en el uso del lenguaje como material para la creación de obras de arte sobre las que poca disensión había acerca de la alta calidad estética que el autor había alcanzado, de acuerdo con los requerimientos del canon occidental en el que se agrupaban las obras consideradas clásicas.

Sin embargo, ya para el último tercio de esa misma centuria, las fronteras de casi todas las ciencias sociales y las humanidades empezaron a dar signos notorios de fragilidad. Si los mismos historiadores pusieron en tela de juicio el concepto de Historia como ciencia rigurosa al cobrar conciencia de la inevitable relatividad de los productos de su quehacer, de igual manera los distintos caminos que emprendieron los escritores y la investigación en el campo de la literatura pusieron en crisis tanto la idea de que la creación literaria, sobre todo la narrativa de ficción, en nada contribuía al conocimiento de la realidad social, como la de que en el término de literatura sólo cabían los textos que se elevaban por encima de los demás por sus logros en el aspecto artístico.

María Alicia Peredo Merlo y Zeyda Rodríguez Morales (20I4). Entre historietas y libros. Literatura popular para la educación sentimental y el bienestar emocional. México: El Colegio de Jalisco-Paidós. 
De tal suerte, mientras los partidarios de la especialización defendieron con vigor la inmovilidad de los límites entre las distintas disciplinas, poco a poco fue imponiéndose el empuje de los que preferían transitar sin pasaporte de un territorio a otro. En 1972, Hayden White aseguraba que la única diferencia real entre la literatura de ficción y la Historia -además de otras disciplinas que empleaban la forma narrativa para comunicar sus conocimientos acerca de las sociedades humanas- era que el historiador "halla" sus relatos, mientras que el escritor de ficción "inventa" los suyos, y que en la tarea del historiador la "invención", es decir, la creación, juega un papel casi tan importante como en la del novelista.

Pero fue en el último tercio del siglo pasado cuando se propagaron las propuestas interdisciplinarias y hasta multidisciplinarias para el estudio de los distintos aspectos que atañen al género humano. En 1989, Règine Robin propuso abolir la distinción entre "círculo amplio" y "círculo restringido" en la producción literaria, pues aseguraba que "ya no hay una literatura [...] sino objetos particulares, cada uno con su manera de inscribirse en la literatura, de producir literatura o de pensar lo literario" (Robin, 1989, p. 47). Este ensanchamiento de los linderos del concepto de literatura, en cierta medida, coincidió con la tendencia en las demás ciencias sociales y humanidades de ampliar sus horizontes hasta recuperar el rango de actividad intelectual a la vez creativa, científica y filosófica, como deseaba Hayden White. La misma Robin propuso la creación de una nueva acepción del campo de la literatura, o mejor, de la escritura en general, que incluyera, además de la

[...] problemática de la literalidad y de la intertextualidad [...] una problemática de la interdiscursividad que se desplegara en todos los campos de lo social y que, en el plano de un discurso transversal, se reformulara de discurso en discurso y se inscribiera tanto en las producciones del 
campo literario como en el discurso político, periodístico o filosófico, etcétera (Robin, 1989, pp. 48-49).

Si partimos de los presupuestos antes dichos, que en la actualidad permiten una extrema interpenetración a las fronteras de las distintas disciplinas hasta casi desvanecerlas, aceptamos entonces que, en última instancia, se trata de diferentes formas de escritura que contribuyen, desde su propia especificidad, al conocimiento del comportamiento humano en sociedad y de sus instituciones, y que nada puede reprochárseles a las autoras de la obra que aquí se trata, al haber dado a las historietas ilustradas y libros de autoayuda la categoría de estructuras narrativas socialmente significativas que, pese a la pobreza de sus logros artísticos o científicos, revelan y facilitan la comprensión de ciertos procesos del comportamiento humano, en este caso el de la educación sentimental, como ellas mismas lo declaran, retomando con muy buen tino el título de la célebre novela que Gustave Flaubert publicó en 1868.

La estructura formal de Entre historietas y libros, cuyo subtítulo, Literatura popular para la educación sentimental y el bienestar emocional, es bastante elocuente, consiste en una introducción, dos capítulos de las diferentes autoras, una conclusión conjunta y una bibliografía común, todo esto en las ciento cincuenta y dos páginas de este volumen.

Suele suceder con casi todos los textos, sin importar mucho el género al que pertenezcan, que sus autores dicen más de lo que quisieron o menos de lo que pretendieron. En este caso sucedió lo primero, por eso haré lo posible por no detenerme mucho en lo que las escritoras hacen explícito en sus respectivos capítulos, para mejor exponer lo que yo, como lector, encontré de común entre ellos.

Antes que nada, debo mencionar la pulcritud metodológica con que manejaron sus distintos materiales de análisis e información, tanto Zeyda Rodríguez Morales y su colabo- 
radora Aída Sofía Estrada Santa Cruz, como María Alicia Peredo Merlo. De otra manera, hubiera sido muy difícil que las dos primeras desmenuzaran ciento veintiséis números de la revista Susy, secretos del corazón, para extraer de ellos todos los elementos necesarios para construir el primer capítulo; o que Alicia Peredo desmontara con pericia cada una de las partes de los cinco libros -La fuerza de Sheccid, de Carlos Cuauhtémoc Sánchez; Verónika decide morir, que escribió el brasileño Carlos Coelho; dos Quiúbole con..., uno para "chavos" y otro para "chavas", según los vocablos que usaron sus autores Yordi Rosado y Gabriela Vargas; y el de John Gray, Los hombres son de Marte, las mujeres son de Venus- que le sirvieron de punto de partida para culminar con éxito la segunda parte del volumen.

En resumen, pues, las autoras combinaron métodos como el análisis del discurso lingüístico y visual, así como históricos, sociológicos, etnográficos, entre otros, para realizar un trabajo hermenéutico fructífero apoyado en lecturas teóricas bien escogidas de varias disciplinas, cuya tarea de descubrirlas por sí mismos dejo a los posibles lectores. Lo que sí creo indispensable es agradecer a Zeyda, Sofía y Alicia la precisión de los términos especializados de que echaron mano, al igual que la claridad y corrección del lenguaje con que comunicaron los resultados de sus respectivas investigaciones.

Ahora bien, no obstante los distintos materiales que conforman cada uno de los capítulos y la diferenciación autoral de los mismos, creo que publicarlos como unidad en un solo volumen ha sido un acierto, pues las preocupaciones de las escritoras son coincidentes, en el sentido de que las guía un genuino interés por encontrar posibles salidas a una problemática cultural que se manifiesta en formas distintas, pero íntimamente interrelacionadas.

A esta problemática la integran el empobrecimiento de la educación, de las relaciones no sólo amorosas, sino humanas 
en general, de la capacidad de distinguir entre conocimiento y experiencia, entre moral y religión, y es de estos asuntos que se ocupa principalmente Entre historietas y libros...

Los dos capítulos que forman dicha obra se avienen perfectamente a otra manera, distinta de la tradicional, de valorar los textos y emitir juicios acerca de los productos culturales discursivos. Zeyda Rodríguez y Sofía Estrada proponen que el éxito que alcanzaron las historietas ilustradas a lo largo de cuatro decenios aproximadamente se debió al placer que ofrecían a quienes las frecuentaban.

Sin embargo, detrás de esta práctica confortable de la lectura, las mismas autoras, sin decirlo con claridad, dejan entrever que no es una práctica del todo inocente, sino que todo el cuerpo de quien lee se dispone a sentir los placeres que describen las historietas.

El conocimiento, pues, no es el objetivo principal de las lectoras, o lectores, sino, más bien, la posibilidad de revivir una experiencia erótica, o, para aquellas que no la han tenido, de imaginarla de acuerdo con lo que se muestra en las ilustraciones. De tal suerte que no es tanto el placer del texto en sí, sino, por una parte, el deseo que se despierta de experimentar el placer corporal que prometen el texto y la ilustración, el discurso lingüístico y el visual, en aquellas que ya lo han sentido y están dispuestas a repetir la experiencia o en las que aún permanecen ajenas a ella y sólo la imaginan, y, por otra parte, el placer moral que debe sentir aquella que ha cumplido con sus principios por encima del placer erótico al haber renunciado a él cuando este está vedado por cualquier circunstancia.

Ahora bien, Alicia Peredo también ajusta sus parámetros de juicio a las corrientes actuales para analizar los libros de autoayuda que conformaron su material de investigación, sólo que se inclina más por la interdiscursividad y resalta la dimensión histórica e ideológica que traslucen dichos textos, sin que esto quiera decir que estas dimensiones 
estén ausentes en el capítulo anterior. De hecho, esta preocupación por situar en un espacio y un tiempo definidos los productos culturales de que se ocupan está presente en ambas partes. Otro rasgo que tienen en común es el de admitir el reconocimiento, la identificación de los lectores en tanto individuos sujetos a deseos, sufrimientos, sentimientos amorosos, y el hecho de que toman las narraciones que caen en sus manos como ejemplo a seguir para orientarse en el mundo, pero, sobre todo, en el mundo de los afectos.

Mediante una serie de entrevistas con estudiantes de secundaria, preparatoria y licenciatura aficionados a la lectura de libros de autoayuda, Alicia Peredo elaboró una serie de cuadros comparativos que resultan muy ilustrativos para comprender el porqué de la preferencia de estas obras entre los estudiantes, pero, también en este caso, me llamó la atención la importancia que dan los entrevistados a los problemas amorosos. Además, no puede ignorarse que uno de los incentivos mayores para la lectura de estos libros es la imposibilidad de que los lectores sean juzgados. Esto trasluce un rechazo a las relaciones personales, y, es justo suponer, sobre todo con los padres.

Ahora bien, aun cuando en ambos capítulos se hace referencia al imaginario, los dos formatos de comunicación vehiculan sólo el imaginario instituido, es decir, lo existente, pero, salvo menciones ocasionales, el otro componente del imaginario, el instituyente, es decir, la parte cambiante de la sociedad, la parte creativa y, por lo tanto, revolucionaria, o por lo menos transgresora, que permite la posibilidad de un cambio que mejore las ya caducas condiciones de vida, se diluye en el hilo de la exposición.

A pesar de esta omisión, la obra evidencia que si bien estas lecturas aparentan cierta utilidad desde el punto de vista de las intenciones estético-educativas de los autores, y aunque están dirigidas a lectores adolescentes y jóvenes, también los adultos las aprecian en alto grado. Por eso, lo 
que resulta más preocupante es que entre estos últimos se cuenten los profesores que están encargados precisamente de la tarea de enseñar a pensar a los jóvenes por su propia cuenta, es decir, que su labor es contraria a su deber, lo cual muestra sus limitaciones culturales e intelectuales, que les impiden darse cuenta de lo nocivo de su influencia en quienes están bajo su cuidado.

Creo que entre las historietas ilustradas y los libros de autoayuda, como lo demuestra la continuidad temporal de estos y las primeras, han tomado por asalto la educación sentimental y hasta cultural de varias generaciones, circunstancia que ha impedido una verdadera experiencia amorosa y prohijado una pérdida de confianza en las relaciones personales para luego buscar refugio en los libros de autoayuda, lo cual ha malogrado la posibilidad de que el hombre contemporáneo se sienta menos oprimido por la lisa cotidianidad actual.

Finalmente, pienso que Entre historietas y libros... constituye una vigorosa denuncia de que los afanes educativos de las lecturas analizadas no dejan de ser mediaciones entre los humanos y sus experiencias vitales, que se convierten, como asegura Giorgio Agamben, en "una experiencia manipulada y guiada como en un laberinto para ratas" (Agamben, 2007, p. 12). Me refiero en especial al ámbito de la experiencia amorosa, cuya fuente principal es el cuerpo, el propio y el del otro, experiencia que se encuentra mediada por una serie de supuestos conocimientos que no han hecho sino expropiársela al ser humano.

Agamben, G. (2007). Infancia e historia. Destrucción de la experiencia y origen de la historia (S. Mattoro, trad.). Buenos Aires: Adriana Hidalgo Editora.

Robin, R. (1989). "Extension et incertitude de la notion de littérature”, en M. Angenot, et al., Théorie Littéraire (pp. 45-49). París: PUF. 